\title{
Disparity in risk factor pattern in premature versus late-onset coronary artery disease: a survey of 15,381 patients
}

This article was published in the following Dove Press journal:

Vascular Health and Risk Management

16 August 2012

Number of times this article has been viewed

\author{
Rona Reibis ${ }^{1,2}$ \\ Andras Treszl ${ }^{3}$ \\ Karl Wegscheider ${ }^{3}$ \\ Kurt Bestehorn ${ }^{4}$ \\ Barbara Karmann ${ }^{4}$ \\ Heinz Völler ${ }^{1,5}$ \\ 'Department of Cardiology, Klinik \\ am See, Rehabilitation Center of \\ Cardiovascular Diseases, Rüdersdorf, \\ ${ }^{2}$ Kardiologische Gemeinschaftspraxis \\ am Park Sanssouci Potsdam, Potsdam, \\ ${ }^{3}$ Department of Medical Biometry \\ and Epidemiology, University \\ Medical Center Hamburg-Eppendorf, \\ Hamburg, ${ }^{4}$ Medical Department, \\ MSD Sharp and Dohme GmbH, Haar, \\ ${ }^{5}$ Center of Rehabilitation Research, \\ University of Potsdam, Potsdam, \\ Germany
}

Background: There are few data available regarding the specificity and modifiability of major cardiovascular (CV) risk factors in patients with premature versus (vs) late-onset coronary artery disease (CAD). This study was designed to analyze and compare these risk factors.

Patients and methods: Data from 15,381 consecutive patients (mean age, $62.3 \pm 11.7$ years; female, 33.8\%) hospitalized with CAD were collected from a large-scale registry (Transparency Registry to Objectify Guideline-Oriented Risk Factor Management) and analyzed. The patients were divided into two groups, depending on age at inclusion: group 1 patients $(n=5725$; mean age, $50.5 \pm 7.2$ years) were males aged $<55$ years and females aged $<65$ years; group 2 patients ( $n=9656$; mean age, 69.4 \pm 7.4 years) were males aged $>55$ years and females aged $>65$ years and had a low-density lipoprotein cholesterol level of $>100 \mathrm{mg} / \mathrm{dL}$ on admission to cardiac rehabilitation. Besides the conventional risk factors, lipoprotein(a) concentrations and glucose tolerance were measured facultatively. Univariate (chi-square test) and multivariate logistic regression models were used.

Results: Cigarette smoking (group 1 at $31.5 \%$ vs group 2 at $9.4 \% ; P<0.001$ ), family history of CAD (group 1 at $43.6 \%$ vs group 2 at $26.5 \% ; P<0.001$ ), and dyslipidemia (group 1 at $92.7 \%$ vs group 2 at $91.8 \% ; P<0.001$ ) were dominant risk factors in the younger group. Arterial hypertension (group 1 at $71.4 \%$ vs group 2 at $87.0 \% ; P<0.001$ ) and diabetes (group 1 at $23.5 \%$ vs group 2 at $30.1 \% ; P<0.001$ ) were dominant risk factors in the older group. Impaired glucose tolerance and diabetes were less frequent in the younger group $\left(P_{\text {trend }}=0.038\right)$, and identical lipoprotein(a) concentration levels of $>30 \mathrm{mg} / \mathrm{dL}$ were found in both groups $(8.0 \% ; P=0.810)$. Modification of lipid profile and blood pressure was more effective in the younger group (low-density lipoprotein cholesterol $<100 \mathrm{mg} / \mathrm{dL}$ : group 1 at $66.3 \%$ vs group 2 at $61.1 \%$; systolic blood pressure $<140 \mathrm{mmHg}$ : group 1 at $91.7 \%$ vs group 2 at $83.0 \% ; P<0.001$ ).

Conclusion: $\mathrm{CV}$ risk factors differ markedly between premature and non-premature CAD. Cardiac rehabilitation provides an opportunity to reinforce secondary prevention after acute coronary syndrome.

Keywords: acute coronary syndrome, premature manifestation, cardiovascular risk factors, diabetes, cholesterol

\section{Introduction}

While the majority of patients with coronary artery disease (CAD) are elderly, the proportion of younger individuals with a premature manifestation of CAD (P-CAD) is continually growing. This is owing to an increase in obesity and diabetes mellitus as well as adverse lifestyles (including smoking and physical inactivity) even in children and young adults. ${ }^{1,2}$ Premature CAD is defined as the first manifestation of CAD in male patients under 55 years of age and in female patients under 65 years of age. ${ }^{3}$
Correspondence: Rona K Reibis Department of Cardiology, Klinik am See, Rehabilitation Center of Cardiovascular Diseases, Seebad 84, D-I 5562 Rüdersdorf/Berlin, Germany Tel +493363878 623

Fax +493363878 624

Email rona.reibis@hotmail.de
(C) 2012 Reibis et al, publisher and licensee Dove Medical Press Ltd. This is an Open Access article which permits unrestricted noncommercial use, provided the original work is properly cited. 
The cumulative burden of conventional modifiable cardiovascular (CV) risk factors including smoking, atherogenic dyslipidemia, diabetes, and being overweight play a key role in the progression of atherosclerotic vascular damage. ${ }^{4}$ Thus, the global risk of genetic, metabolic, and environmental risk factors determines the age of onset of CAD.

The present study was designed to analyze and compare major CV risk factors for patients with P-CAD and those with late-onset CAD. Furthermore, the authors assessed the target value attainment during an inpatient cardiac rehabilitation program and determined the measurement frequency of extended CV risk factors including lipoprotein(a) [Lp(a)] and impaired glucose tolerance (IGT) in the daily routine of German cardiac rehabilitation centers.

\section{Methods}

\section{Patients}

In total, 15,381 consecutive patients with CAD (mean age, $62.3 \pm 11.7$ years; $33.8 \%$ female) who were hospitalized for inpatient cardiac rehabilitation in 101 German rehabilitation centers were included in a nationwide multicentric longitudinal registry (the Transparency Registry to Objectify Guideline-Oriented Risk Factor Management [TROL]). Patients were divided into two groups, depending on age at inclusion: group 1 had patients with P-CAD (men aged $<55$ years, women aged $<65$ years); group 2 had patients with late-onset CAD (men aged $>55$ years, women aged $>65$ years) and low-density lipoprotein cholesterol (LDL-C) levels $>100 \mathrm{mg} / \mathrm{dL}(>2.6 \mathrm{mmol} / \mathrm{L})$ on admission to a cardiac rehabilitation center.

On admission, anthropometric parameters (age, gender, body mass index), type of coronary index event (ST elevation myocardial infarction [STEMI], non-STEMI, unstable angina, stable angina), and revascularization procedure (percutaneous coronary intervention, coronary artery bypass grafting [CABG]) or conservative strategy were assessed. Furthermore, comorbidities including peripheral arterial disease, previous stroke, carotid stenosis $>50 \%$, and chronic obstructive pulmonary disease were documented.

\section{Risk factor assessment and target values}

To assess the CV risk profile, total cholesterol, LDL-C, and high-density lipoprotein cholesterol (HDL-C) levels, triglyceride (TG) level, and arterial blood pressure (BP) were determined in all patients. Lipid levels, BP, and medication were recorded on admission and again on discharge. In respect to medication, the observation comprised beta-blockers,
ACE inhibitors, angiotensin II type 1 receptor blockers, statins, and cholesterol resorption antagonists.

Furthermore, family history of premature atherosclerosis, smoking behavior, and glucometabolic state (manifest diabetes mellitus) was assessed. Facultatively, the emerging CV risk factors $\mathrm{Lp}(\mathrm{a})$ and IGT were determined. IGT was defined as a fasting plasma glucose level of $\geq 100 \mathrm{mg} /$ $\mathrm{dL}$ but $<126 \mathrm{mg} / \mathrm{dL}$ or a 2 -hour oral glucose tolerance test (OGTT) plasma level of $\geq 140 \mathrm{mg} / \mathrm{dL}$ but $<200 \mathrm{mg} / \mathrm{dL}$. Diabetes was characterized by a fasting plasma glucose level $\geq 126 \mathrm{mg} / \mathrm{dL}$ and/or a 2-hour OGTT plasma glucose level of $\geq 200 \mathrm{mg} / \mathrm{dL} .^{5}$

The target BP value for patients after acute coronary syndrome (ACS) was $<140 / 90 \mathrm{mmHg}$. The target HDL-C levels were $>40 \mathrm{mg} / \mathrm{dL}(>1 \mathrm{mmol} / \mathrm{L})$ and the target LDL-C levels were $<100 \mathrm{mg} / \mathrm{dL}(<2.6 \mathrm{mmol} / \mathrm{L})$. All patients were to achieve a fasting glucose level of $<126 \mathrm{mg} / \mathrm{dL}(<7.0 \mathrm{mmol} / \mathrm{L})$ and a TG level of $<150 \mathrm{mg} / \mathrm{dL}(<1.7 \mathrm{mmol} / \mathrm{L})$.

The local laboratories at the respective rehabilitation centers, which are obliged to take part in quality control measures at regular intervals, performed the laboratory tests.

\section{Cardiac rehabilitation program}

In Germany, the vast majority of patients at high cardiac risk - in particular, after ACS or CABG - are entitled to undergo inpatient rehabilitation therapy. This is conducted in specialized institutions and usually lasts 3-4 weeks. According to recent guidelines, rehabilitation programs include individualized physical training, disease information, structured teaching programs for reduction of $\mathrm{CV}$ risk factors, and psychological support. ${ }^{6}$ The protocol of the present study was reviewed and approved by the ethics review board of the Bavarian Chamber of Physicians, Munich.

\section{Statistical analysis}

Discrete variables are given as counts and percentages, and continuous variables are given as mean plus or minus standard deviation. Univariate between-group comparisons for nominal variables were performed using chi-square test, Cochran-Armitage trend tests were used for ordinal variables, and estimation of variance ( $F$-test) was used for continuous variables. Logistic regression analysis with backward selection was applied to determine the simultaneous influence of conventional $\mathrm{CV}$ risk factors on belonging to the premature or the late-onset CAD group. A nominal $P$-value of $<0.05$ was considered statistically significant. No adjustment for multiplicity was performed. Analyses were performed using statistical software (SAS, v 9.2; SAS Institute Inc, Cary, NC). 


\section{Results}

Group 1 patients had a mean age of $50.5 \pm 7.2$ years, while the mean age of group 2 patients was $69.4 \pm 7.4$ years $(P<0.001)$. Female gender, a higher body mass index, STEMI, non-STEMI, and interventional revascularization during the acute coronary event were found to be more frequent in group 1. Group 2 patients demonstrated a significantly higher proportion of all comorbidities, including peripheral arterial disease, stroke, carotid stenosis, and chronic obstructive pulmonary disease, and group 2 patients were treated to a greater extent with aortocoronary bypass grafting during the target coronary event. Because of a complex revascularization approach in some patients (primary percutaneous coronary intervention of target vessel and consecutive $\mathrm{CABG}$ ), the summary of interventions exceeds $100 \%$ in both age groups (Table 1).

In univariate analysis, current cigarette smoking and a positive family history of CAD were discovered in a higher proportion in the younger group, whereas arterial hypertension predominated in group 2 (Table 2). On admission, almost a quarter of patients in the younger group offered manifest diabetes mellitus, while every third late-onset patient was diabetic (group 1 at $23.5 \%$ versus [vs] group 2 at $30.1 \%$; $P<0.001)$. The OGTT was performed in $20.0 \%$ of group 1

Table I Baseline characteristics and functional parameters

\begin{tabular}{|c|c|c|c|}
\hline & $\begin{array}{l}\text { Group I } \\
(n=5725)\end{array}$ & $\begin{array}{l}\text { Group } 2 \\
(n=9656)\end{array}$ & $P$-value \\
\hline Age (years)* & $50.5 \pm 7.2$ & $69.4 \pm 7.4$ & $<0.001$ \\
\hline Female (\%) & 37.6 & 31.6 & $<0.001$ \\
\hline Height $(\mathrm{cm})^{*}$ & $171.9 \pm 9.3$ & $169.4 \pm 9.2$ & $<0.001$ \\
\hline Weight $(\mathrm{kg})^{*}$ & $82.8 \pm 15.6$ & $78.5 \pm 13.5$ & $<0.001$ \\
\hline Body mass index $\left(\mathrm{kg} / \mathrm{m}^{2}\right)^{*}$ & $30.0 \pm 4.7$ & $27.4 \pm 4.1$ & $<0.001$ \\
\hline \multicolumn{4}{|l|}{ Diagnosis } \\
\hline STEMI (\%) & 55.3 & 39.9 & $<0.001$ \\
\hline NSTEMI (\%) & 15.0 & 11.3 & $<0.001$ \\
\hline Unstable AP (\%) & 18.8 & 24.0 & $<0.001$ \\
\hline Stabile CAD & 18.9 & 24.8 & $<0.001$ \\
\hline \multicolumn{4}{|l|}{ Therapy } \\
\hline Primary PCl (\%) & 67.2 & 48.6 & $<0.001$ \\
\hline CABG (\%) & 38.1 & 56.7 & $<0.001$ \\
\hline Conservative (\%) & 22.3 & 28.9 & $<0.001$ \\
\hline \multicolumn{4}{|l|}{ Comorbidity } \\
\hline PAD (\%) & 6.9 & 13.9 & $<0.001$ \\
\hline Stroke (\%) & 7.2 & 13.1 & $<0.001$ \\
\hline Carotid stenosis $>50 \%(\%)$ & 3.1 & 8.2 & $<0.001$ \\
\hline COPD (\%) & 7.1 & 11.3 & $<0.001$ \\
\hline
\end{tabular}

Note: *Data presented as mean plus or minus standard deviation.

Abbreviations: STEMI, ST elevation myocardial infarction; NSTEMI, non-ST elevation myocardial infarction; AP, angina pectoris; CAD, coronary artery disease; $\mathrm{PCl}$, percutaneous coronary intervention; CABG, coronary artery bypass grafting; COPD, chronic obstructive pulmonary disease; PAD, peripheral arterial disease.
Table 2 Conventional and extended cardiovascular risk factors

\begin{tabular}{|c|c|c|c|}
\hline & $\begin{array}{l}\text { Group I } \\
(n=5725)\end{array}$ & $\begin{array}{l}\text { Group } 2 \\
(n=9656)\end{array}$ & $P$-value \\
\hline \multicolumn{4}{|l|}{ Conventional risk factors } \\
\hline Dyslipidemia (\%) & 92.7 & 91.8 & 0.04 \\
\hline Arterial hypertension (\%) & 71.4 & 87.0 & $<0.001$ \\
\hline Current smoker (\%) & 31.5 & 9.4 & $<0.001$ \\
\hline Former smoker (\%) & 48.7 & 40.0 & $<0.001$ \\
\hline Family history (\%) & 43.6 & 26.5 & $<0.001$ \\
\hline Diabetes mellitus (\%) & 23.5 & 30.1 & $<0.001$ \\
\hline \multicolumn{4}{|l|}{ OGTT $^{\mathrm{a}}$} \\
\hline Performed [n (\%)] & $842(20.0 \%)$ & $393(6.1 \%)$ & $<0.001$ \\
\hline IGT [n (\%)] & $94(11.2)$ & $63(16.0)$ & 0.038 \\
\hline Diabetes [n (\%)] & $17(2.1)$ & $9(2.3)$ & 0.038 \\
\hline \multicolumn{4}{|l|}{ Lp(a) } \\
\hline Determined [n (\%)] & 1154 (20.2) & $446(4.8)$ & $<0.001$ \\
\hline$>30$ mg/dL [n (\%)] & $90(7.8)$ & $38(8.2)$ & 0.810 \\
\hline Determined $\mathrm{Lp}(\mathrm{a})(\mathrm{mg} / \mathrm{dL})^{\mathrm{b}}$ & $10.8 \pm 20.9$ & $10.3 \pm 22.3$ & 0.022 \\
\hline
\end{tabular}

Notes: aln patients without documented diabetes; bdata presented as mean plus or minus standard deviation.

Abbreviations: OGTT, oral glucose tolerance test; IGT, impaired glucose tolerance; $\operatorname{Lp}(\mathrm{a})$, lipoprotein(a).

patients compared with $6.1 \%$ of group 2 patients without a documented history of glucometabolic disorder. Of these patients, IGT was identified in every tenth patient (11.2\%) in group 1 and in every sixth patient (16.0\%) in group 2. Manifest diabetes was identified by OGTT in $2.0 \%$ of group 1 patients vs $2.3 \%$ of group 2 patients $\left(P_{\text {trend }}=0.038\right)$. Lp(a) was determined in $20.2 \%$ of group 1 patients and $4.8 \%$ of group 2 patients, with identical pathologic levels $>30 \mathrm{mg} / \mathrm{dL}$ in both groups $(8.0 \%)$.

In multivariate analysis, arterial hypertension and diabetes favored late-onset $\mathrm{CAD}$, whereas particularly current and former cigarette smoking as well as family history of $\mathrm{CAD}$ were significantly correlated with premature $\mathrm{CAD}$ (Figure 1).

\section{Risk factor management}

On admission to cardiac rehabilitation, the mean systolic BP of group 1 patients was lower than that of group 2 patients (group 1 at $129.7 \pm 20.6 \mathrm{mmHg}$ vs group 2 at $135.2 \pm 21.0 \mathrm{mmHg}$; $P<0.001$ ), whereas the mean diastolic BP was higher (group 1 at $79.3 \pm 11.8 \mathrm{mmHg}$ vs group 2 at $77.7 \pm 11.3 \mathrm{mmHg}$; $P<0.001)$ in the younger patients. Further BP control was achieved in both age groups (systolic BP: $-5.2 \mathrm{mmHg}$ in group 1 and $-4.8 \mathrm{mmHg}$ in group $2, P<0.001$; diastolic BP: $-10.3 \mathrm{mmHg}$ in group 1 and $-12.0 \mathrm{mmHg}$ in group 2, $P=0.074$ ). All lipid fractions could be optimized during cardiac rehabilitation. BP and lipid profile on admission and on discharge are demonstrated in Table 3. 


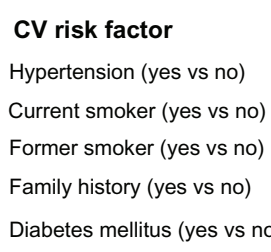

$\begin{array}{cc}\text { OR } & \text { Cl } \\ 2.004 & (1.825-2.201) \\ 0.187 & (0.166-0.210) \\ 0.489 & (0.450-0.532) \\ 0.459 & (0.423-0.499) \\ 1.222 & (1.117-1.338)\end{array}$

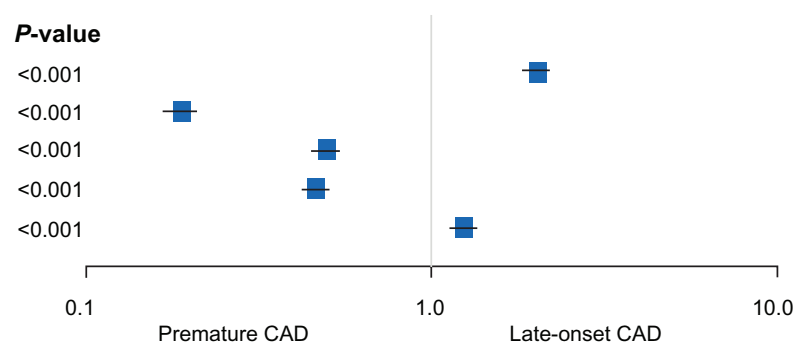

Figure I Cardiovascular (CV) risk factors associated with premature versus (vs) late-onset coronary artery disease (CAD). Abbreviations: $\mathrm{OR}$, odds ratio; $\mathrm{Cl}$, confidence interval.

Target value attainment differed significantly between groups. LDL-C levels $<100 \mathrm{mg} / \mathrm{dL}$ on discharge were more frequent in group 1, whereas TG levels $<150 \mathrm{mg} / \mathrm{dL}$ and HDL-C levels $>40 \mathrm{mg} / \mathrm{dL}$ was found to be more frequent in group 2. On discharge from rehabilitation the proportion of systolic BPs below $140 \mathrm{mmHg}$ and diastolic BPs below $90 \mathrm{mmHg}$ was high (Figure 2).

ACE inhibitors (group 1 at $77.1 \%$ vs group 2 at $78.9 \%$; $P=0.01$ ) were given to a lesser extent in group 1 than in group 2; beta-blockers (group 1 at $92.2 \%$ vs group 2 at $88.4 \% ; P<0.001$ ) were given to a greater extent in group 1 than in group 2. The prescription of angiotensin II type 1 receptor blockers was comparably low between both groups (group 1 at $13.4 \%$ vs group 2 at $12.5 \% ; P=0.133$ ), 94.7\% of group 1 patients vs $89.1 \%$ of group 2 patients $(P<0.001)$ received statins, and $39.0 \%$ of group 1 patients vs $45.5 \%$ of group 2 patients received cholesterol resorption inhibitors $(P<0.001)$.

\section{Discussion}

There were three important findings from this study. First, based on 15,381 consecutive ACS patients, the authors found considerable difference of $\mathrm{CV}$ risk factor pattern between patients with P-CAD and patients with late-onset CAD. Second, in both groups the proportion of patients with diabetes or IGT was notably high; nevertheless, the frequency of routine performance of OGTT in post-ACS patients without known glucometabolic disorder is limited. Finally, cardiac rehabilitation after an acute coronary event is a powerful tool to optimize attainment of target BP values in both age groups. The influence of cardiac rehabilitation is shown predominantly in the younger group, whereas lipid profile, particularly TG and HDL-C levels, is less modifiable during the 3 weeks of cardiac rehabilitation.

\section{Risk factor pattern of patients with premature vs late-onset CAD}

Corresponding to other data, ${ }^{7}$ the authors found a "malignant triad" of smoking, LDL-C-related dyslipidemia, and family history of CAD particularly in younger patients. The proportion of current or former cigarette smokers in group 1 was notable at about $80 \%$, whereas only $49.4 \%$ of group 2 patients reported regular current or former tobacco consumption. This indicates an age-dependent divergent importance of the connection between smoking and microvascular damage. Smoking initiates and promotes atherosclerosis by altering cardiac hemodynamics, causing dyslipidemia and increased production of free oxygen radicals by oxidative stress of nicotine. ${ }^{7}$ According to the INTERHEART study, ${ }^{4}$ cigarette smoking is associated with a higher $\mathrm{CV}$ risk than diabetes,

Table 3 Trend of arterial hypertension, lipid profile, and plasma glucose level during cardiac rehabilitation

\begin{tabular}{|c|c|c|c|c|c|c|}
\hline & \multicolumn{3}{|l|}{ Admission } & \multicolumn{3}{|l|}{ Discharge } \\
\hline & Group I & Group 2 & $\overline{P \text {-value }}$ & Group I & Group 2 & $P$-value \\
\hline RR syst $(\mathrm{mmHg})$ & $129.7 \pm 20.6$ & $135.2 \pm 21.0$ & $<0.001$ & $119.5 \pm 13.2$ & $123.3 \pm 14.0$ & $<0.001$ \\
\hline $\mathrm{RR}$ diast $(\mathrm{mmHg})$ & $79.3 \pm 11.8$ & $77.7 \pm 11.3$ & $<0.001$ & $74.1 \pm 8.6$ & $73.0 \pm 8.7$ & $<0.001$ \\
\hline Total-C (mg/dL) & $199.8 \pm 47.6$ & $215.3 \pm 38.6$ & $<0.001$ & $164.4 \pm 33.4$ & $168.5 \pm 33.1$ & $<0.001$ \\
\hline LDL-C (mg/dL) & $121.9 \pm 38.5$ & $137.6 \pm 29.0$ & $<0.001$ & $91.8 \pm 26.6$ & $97.2 \pm 26.9$ & $<0.001$ \\
\hline HDL-C (mg/dL) & $42.5 \pm 13.3$ & $44.7 \pm 12.6$ & $<0.001$ & $43.0 \pm 12.0$ & $44.8 \pm 12.0$ & $<0.001$ \\
\hline $\mathrm{TG}(\mathrm{mg} / \mathrm{dL})$ & $172.8 \pm 78.5$ & $157.5 \pm 65.4$ & $<0.001$ & $149.9 \pm 66.7$ & $134.3 \pm 53.2$ & $<0.001$ \\
\hline $\mathrm{FG}(\mathrm{mg} / \mathrm{dL})$ & $102.0 \pm 27.9$ & $108.6 \pm 30.0$ & $<0.001$ & $99.7 \pm 23.1$ & $104.5 \pm 22.8$ & $<0.001$ \\
\hline
\end{tabular}

Note: Data other than $P$-values are presented as mean plus or minus standard deviation.

Abbreviations: RR syst, systolic blood pressure; RR diast, diastolic blood pressure; Total-C, total cholesterol; LDL-C, low-density lipoprotein cholesterol; HDL-C, highdensity lipoprotein cholesterol; TG, triglyceride; FG, fasting glucose plasma level. 

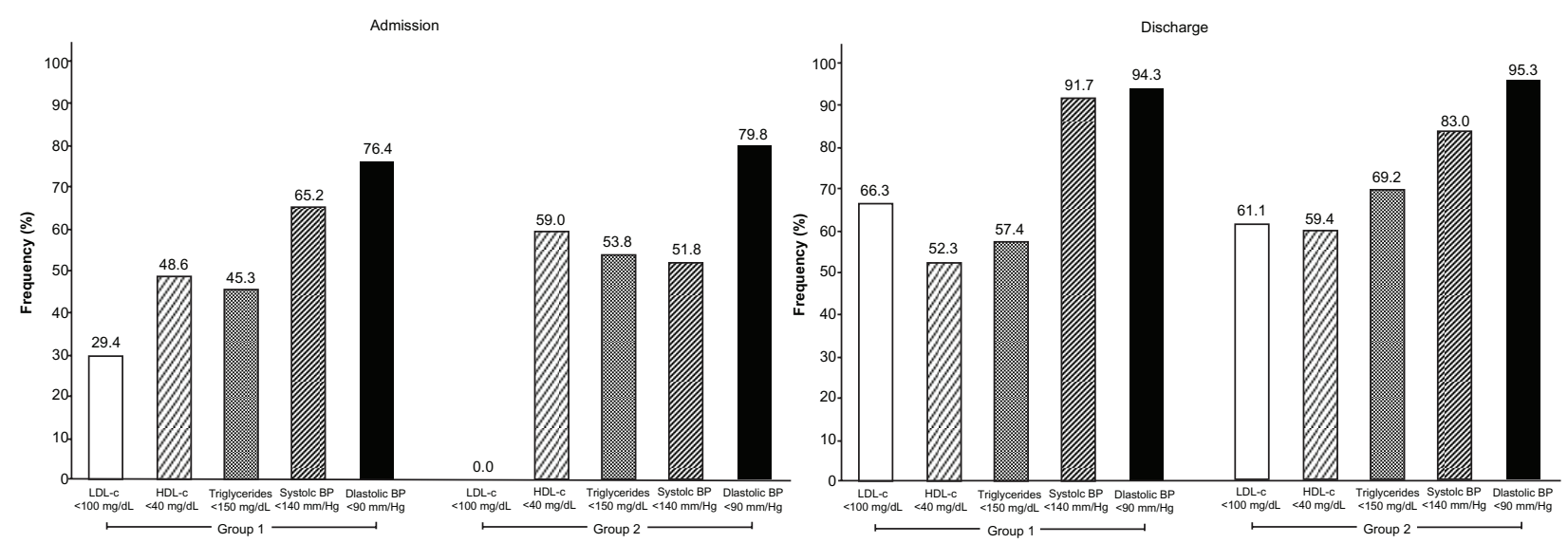

Figure 2 Target value attainment after cardiac rehabilitation: comparison of groups I and 2 .

Abbreviations: LDL-C, low-density lipoprotein cholesterol; HDL-C, high-density lipoprotein cholesterol; BP, blood pressure.

arterial hypertension, abdominal obesity, and adverse psychosocial factors, and it was outperformed only by a raised apolipoprotein B/apolipoprotein A-I ratio. Predominantly young smoking women are at risk for premature manifestation of CAD followed by a significant reduction in life expectancy. ${ }^{8,9}$ Despite this, the results of the three EUROASPIRE surveys demonstrate an increase in smoking rates, particularly in younger female patients, from 1996 to 2007. ${ }^{2}$ Panagiotakos et $\mathrm{al}^{10}$ reported that cigarette smoking was the most important risk factor for having a myocardial infarction in individuals under the age of 36 years, with a sixfold increased risk for reinfarction after the first acute coronary event. In comparison with nonsmokers, cigarette smoking is associated with an average lifetime loss of 10 years. ${ }^{11}$ Although an excess risk continues for more than 20 years after smoking cessation, ${ }^{12}$ the quitting after $\mathrm{CABG}$ gained approximately 3 years' life expectancy and has shown to be the most important therapeutic approach in the follow-up of surgical revascularization. ${ }^{13} \mathrm{In}$ 2007 , Germany started a smoking restriction in the public and hospitality sectors. After just 1 year, this law implementation was associated with a $13.3 \%$ decline in angina pectoris and an $8.6 \%$ decline in myocardial infarction, saving approximately 7.7 million Euros in hospitalization costs. ${ }^{14}$ Thus, smoking cessation and interdisciplinary precautions to prevent smoking relapse should remain stringent goals, particularly in young patients with CAD.

Furthermore, young patients are characterized by a higher incidence of LDL-C-related dyslipidemia; the proportion $(>90 \%)$ is comparable with those of other large-scale registries. ${ }^{7}$ Although dyslipidemia is strongly associated with a genetic component, modifiable cofactors including physical inactivity and being overweight have been shown to reinforce lipid profile disorders. ${ }^{15}$
A comparable adverse causal complex is applicable for arterial hypertension, which was found in the majority of younger patients (although to a lesser extent than in older patients). In such a constellation, arterial hypertension, dyslipidemia, smoking, and being overweight can act as a trigger for the manifestation of CAD, particularly in younger patients. ${ }^{16}$

Besides remediable $\mathrm{CV}$ risk parameters, the authors found an impressive proportion of group 1 patients with a positive family history of P-CAD. Andresdottir et a ${ }^{17}$ reported that independently of obesity, cholesterol, and BP levels, up to $16.6 \%$ of coronary events were attributable to family history of CAD. The importance of family history is considerable, particularly in young women; nevertheless, young women with a genetic background of CAD generally demonstrate less CV risk awareness and worse lifestyle behaviors than those without family history of CAD.$^{18} \mathrm{~A}$ large-scale study including more than 50,000 individuals reported that paternal as well as maternal history of myocardial infarction up to a manifestation age $>80$ years is associated with increased CAD risk for the following generation. ${ }^{19}$ The highest risk was described for women aged $<50$ years with premature maternal infarction, with an odds ratio of 2.57 , which is comparable with the prognostic impact of smoking or manifest diabetes. In the presence of coexisting $\mathrm{CV}$ risk factors the importance of family history of CAD is further increased. ${ }^{20}$

\section{Glucometabolic disorders}

Type 2 diabetes constitutes one of the common final results of sedentary behavior, obesity, and adverse eating behavior, whereas each point separately offers an additional major $\mathrm{CV}$ risk factor. ${ }^{21,22}$ In the light of increased mortality of diabetics with ACS compared with nondiabetic patients, 
the fundamental goal should be the evaluation of a pathologic glucose metabolism by a routinely performed OGTT. ${ }^{23}$ Astonishingly, particularly in the older group the OGTT was performed quite rarely across the German rehabilitation centers.

In the observed patients, the percentage of diabetics was comparable with prior studies, with a proportion of 13\%-30\%. ${ }^{2,20,24}$ The OGTT identified IGT, a prognostic parameter, ${ }^{25}$ in a high percentage of patients and predominantly in the older group. In the Euro Heart Survey on diabetes and the heart, ${ }^{26}$ the rate of patients with unknown IGT who were referred to undergo elective or acute angiography was remarkable at 39\%. This high prevalence of glucometabolic disorders is confirmed by other study groups. ${ }^{27}$ Lankisch et $\mathrm{al}^{28}$ reported that if all patients with a fasting glucose of $\geq 90 \mathrm{mg} / \mathrm{dL}$ would be referred to undertake the OGTT, the identification rate of diabetes would be increased from $28.1 \%$ (usually the OGTT is performed if the fasting glucose level is $\geq 126 \mathrm{mg} / \mathrm{dL}$ ) to $93.8 \%$. Notably, the OGTT performed immediately after a STEMI did not provide reliable information on the long-term glucometabolic state; thus, a delay after the acute coronary event may be desirable. ${ }^{29}$

\section{Extended CV risk factors}

In young adults with P-CAD, intravascular thrombogenesis as a complex interplay of a procoagulant state, fibrinolysis, endothelial dysfunction, and inflammation may be an additional parameter besides conventional $\mathrm{CV}$ risk factors. ${ }^{30}$ A near normal LDL-C level can be found in up to $40 \%$ of $\mathrm{CAD}$ patients; thus, discussion regarding emerging $\mathrm{CV}$ risk factors - including high-sensitivity C-reactive protein, $\mathrm{Lp}(\mathrm{a})$, and homocysteine - causing the inflammation theory of CAD is ongoing. ${ }^{31}$

$\mathrm{Lp}(\mathrm{a})$ is a genetically determined lipid fraction that has proven to be a relevant cofactor in the genesis and progression of atherosclerosis. The pharmacological approach in lowering $\mathrm{Lp}$ (a) levels is still limited, although reducing the oxidized LDL-C levels in patients with pathologic Lp(a) concentration levels may be of prognostic influence. ${ }^{32}$ Additionally, more recently a genetic background for the prognostic implication of $\mathrm{Lp}(\mathrm{a})$ independent of LDL-C has been described. ${ }^{33}$ The increased awareness of accompanying risk factors in younger patients might explain the higher rate of $\mathrm{Lp}(\mathrm{a})$ measurements in group 1 during cardiac rehabilitation; however, the $\mathrm{Lp}(\mathrm{a})$ concentration was only determined in every fifth group 1 patient and in $<5 \%$ of group 2 patients. Whereas other authors describe a higher rate of pathologic Lp(a) levels in P-CAD patients, ${ }^{34}$ the present authors found comparable increased values across both age groups. However, while $92 \%$ of young patients revealed an elevated LDL-C level, a determination of $\mathrm{Lp}(\mathrm{a})$ levels and other risk factors should be used to estimate overall risk for CAD progression. In the case of elevated $\mathrm{Lp}$ (a) in patients with $\mathrm{P}-\mathrm{CAD}$, an aggressive lipid-lowering treatment with statins at low to normal values should be aimed for. ${ }^{35}$

\section{Risk factor management}

Cardiac rehabilitation provides a substantial benefit in management of major CV risk factors including lipid profile and BP in patients with CV diseases. ${ }^{36}$ The 3- to 4-week inpatient cardiac rehabilitation in Germany is designed according to the recommendations of national and European Society of Cardiology guidelines ${ }^{37}$ and offers the opportunity not only to monitor patients after ACS but also to reinforce secondary preventive approaches in the long-term treatment of CAD. Cardiac rehabilitation includes a gradual increase in activity levels, as well as continuous and individually focused information about effective lifestyle modification, smoking cessation, and dietary counseling.

Although recent guidelines recommend target BP values of $<130 / 80 \mathrm{mmHg}$ for patients with manifest CAD, the present authors focused on conservative values of $<140 / 90 \mathrm{mmHg}$ because of the limited treatment period during cardiac rehabilitation. In the TROL, after a 3 -week inpatient cardiac rehabilitation program, BP values of $<140 / 90 \mathrm{mmHg}$ were attained in a high proportion of all patients, with a predominance shown in younger patients because of higher baseline BP levels in the late-onset CAD group. Only diastolic BP in group 2 patients could be further optimized, which can be explained by an even lower diastolic $\mathrm{BP}$ in older patients due to increased vascular stiffness. The comparable medication across both groups might be a crucial point of reduced efficacy in BP therapy, indicating the need for intensified management of hypertensive patients of a particularly advanced age.

The European Society of Cardiology's guidelines on CVD prevention in clinical practice have been recently updated. ${ }^{37}$ Of note, these guidelines already suggest stronger lipid goals of LDL-C for all ACS patients, irrespective of a glucometabolic situation below $70 \mathrm{mg} / \mathrm{dL}$ (1.8 mmol/L). Regarding LDL-C targets, the present authors still focused on the $100 \mathrm{mg} / \mathrm{dL}(2.6 \mathrm{mmol} / \mathrm{L})$ threshold according to National Cholesterol Education Program - Adult Treatment Panel III (NCEP ATP III) criteria. ${ }^{38}$ The NCEP ATP III target value was achieved by a moderate proportion of both patient groups during cardiac rehabilitation. An early and intensive statin 
therapy is superior to moderate statin doses, particularly in patients after ACS, and leads to a reduced mortality by $-25 \%$ over a follow-up period of 2 years. ${ }^{39}$ Compared with other large registries (eg, the Global Registry of Acute Coronary Events or the Register of Information and Knowledge about Swedish Heart Intensive Care Admissions) with a prescription rate of $<50 \%$, in the TROL the statin therapy rates of $94.7 \%$ and $89.1 \%$ in groups 1 and 2, respectively, can hardly be increased ${ }^{40,41}$ Because of a high prescription rate of statins, the LDL-C lipid fraction demonstrated a favorable trend during cardiac rehabilitation; however, the less influenceable HDL-C and fasting TG levels remained inadequate. Plasma TG levels in particular were above the NCEP ATP III limits in every second patient from group 1 , implying a prolongation of comprehensive lifestyle change. Nevertheless, there is no strong evidence that fasting TG levels $<150 \mathrm{mg} / \mathrm{dL}$ are associated with a decreased coronary risk. It remains to be analyzed whether non-fasting TG levels are better indicators for further events. ${ }^{38}$ Similarly, the target values for HDL-C could only be attained in over half of the patients in both groups. Because of the independent prognostic impact of TG and reduced HDL-C on CAD progression these lipid values, as well as LDL-C, should be carefully observed. ${ }^{42}$

To identify patients with a constellation of high $\mathrm{CV}$ risks and offer them eligible and sustentative interventions is highly desirable. In patients with established CAD, participation in regular, individually designed public training programs has been proven to reduce plasma lipids, inflammation parameters, excess weight, depression, and psychosocial stress levels. ${ }^{43,44}$ Aerobic exercise training is associated with reduced mortality, in healthy individuals, those with a CV risk profile, and cardiac patients. ${ }^{45}$ Recent European guidelines recommend physical activity at a mild to moderate intensity for 30 minutes at least three times a week. ${ }^{37}$

In Germany, many health insurance companies support preventive medicine sports groups with regular training sessions within the framework of heart disease management programs. ${ }^{46}$

Although there is compelling evidence of beneficial outcomes, the divergence between guideline-based recommendations and the clinical reality in treatment of CAD patients is worrisome. The large-scale European REACH (Reduction of Atherothrombosis for Continued Health) registry demonstrated a $24 \%$ reduction in CV event rate and an $11 \%$ reduction in mortality if conventional risk factors are strictly adhered to; nevertheless, this treatment is deemed to be adequate in only $60 \%$ of patients with established atherosclerotic disease. ${ }^{47}$ The three EUROASPIRE surveys ${ }^{2,48}$ describe a continuing gap between theory and practice in lifestyle interventions and drug therapy. Thus, there is an urgent need for increased sensibility regarding CV risk factor control and enhanced individual responsibility in CAD treatment.

\section{Study limitations}

This study has several limitations. First, the study was conducted as a prospective observational study, performed in German rehabilitation clinics. The results reflect the conditions of selected patients with stringent observation of risk factors, lifestyle, and medication. Participation in the cardiac rehabilitation was voluntary and not without a selection bias. Second, in the given registry the authors exclusively focused on documentation of age-dependent $\mathrm{CV}$ risk factors and their modifiability during inpatient cardiac rehabilitation. Follow-up and outcome data after optimization of $\mathrm{CV}$ risk factors were missing.

Differences regarding the physical activity level were not registered and should be acknowledged. Furthermore, the authors do not have data regarding eating behavior in both groups. As only instantaneous data on the constellation of risk during cardiac rehabilitation were collected, the authors do not have information regarding continuous data - including exercise and dietary data prior to admission.

Because of the limited measurement rate, reliable information regarding $\mathrm{Lp}$ (a) levels was missed. Third, there was an inhomogeneity in characteristics of CAD within the groups, including patients with stable $\mathrm{CAD}$, those after an acute coronary event, and those after interventional and/or surgical revascularization. Finally, newly described risk factors such as high-sensitivity C-reactive protein were excluded from the observation because of the high percentage of surgically revascularized patients with postoperatively increased C-reactive protein levels.

\section{Conclusion}

In patients with $\mathrm{P}-\mathrm{CAD}$, cigarette smoking and family history of $\mathrm{CAD}$ were found to be more frequent in younger patients than in their older counterparts. Even in young patients, the incidence of glucometabolic disorder, including IGT and manifest diabetes, is alarming high. Because of the synergistic effect of $\mathrm{CV}$ risk factors and positive family history, the reduction of modifiable risk parameters and smoking cessation is strongly required - particularly in younger patients with P-CAD. Cardiac rehabilitation after an acute coronary event is a powerful tool to optimize attainment of target lipid profile and BP values in both age groups. The influence of cardiac rehabilitation is 
shown predominantly in the younger group, and it may have a positive effect on patient-related outcome.

\section{Acknowledgments}

The TROL was run in cooperation with the German Society for Prevention and Rehabilitation of Cardiovascular Diseases. The registry was supported by an educational grant-inaid from MSD Sharp and Dohme GmbH, Munich-Haar, Germany.

\section{Disclosure}

$\mathrm{KB}$ and $\mathrm{BK}$ are employees of MSD. No competing financial interests exist for any authors. HV received travel expenses from MSD Sharp and Dohme GmbH and Essex Pharma $\mathrm{GmbH}$. Parts of this work have been presented at the annual congress of the European Society of Cardiology in 2005 in Stockholm, Sweden.

\section{References}

1. Franklin BA, Trivax JE, Vanhecke TE. New insights in preventive cardiology and cardiac rehabilitation. Curr Opin Cardiol. 2008;23(5): $477-486$.

2. Kotseva K, Wood D, De Backer G, De Bacquer D, Pyörälä K, Keil U; for EUROASPIRE Study Group. Cardiovascular prevention guidelines in daily practice: a comparison of EUROASPIRE I, II, and III surveys in eight European countries. Lancet. 2009;373(9667):929-940.

3. Wood D, De Backer G, Faergeman O, Graham I, Mancia G, Pyörälä K. Prevention of coronary heart disease in clinical practice: recommendations of the Second Joint Task Force of European and other Societies on Coronary Prevention. Eur Heart J. 1998;19(10):1434-1503.

4. Yusuf S, Hawken S, Ounpuu S, et al; for INTERHEART Study Investigators. Effect of potentially modifiable risk factors associated with myocardial infarction in 52 countries (the INTERHEART study): case-control study. Lancet. 2004;364(9438):937-952.

5. Department of Noncommunicable Disease Surveillance, World Health Organization. Definition, Diagnosis and Classification of Diabetes Mellitus and Its Complications: Part 1. Diagnosis and Classification of Diabetes Mellitus. Report no WHO/NCD/NCS/99.2. Geneva: World Health Organization; 1999.

6. Karoff M, Held K, Bjarnason-Wehrens B. Cardiac rehabilitation in Germany. Eur J Cardiovasc Prev Rehabil. 2007;14(1):18-27.

7. Schoenenberger AW, Radovanovic D, Stauffer JC, et al; for AMIS Plus Investigators. Acute coronary syndromes in young patients: presentation, treatment and outcome. Int J Cardiol. 2011;148(3):300-304.

8. Heitzer T, Meinertz T. Prevention of coronary heart disease: smoking. Z Kardiol. 2005;94 Suppl 3:III/30-42. German.

9. Grundtvig M, Hagen TP, German M, Reikvam A. Sex-based differences in premature first myocardial infarction caused by smoking: twice as many years lost by women as by men. Eur J Cardiovasc Prev Rehabil. 2009;16(2):174-179.

10. Panagiotakos DB, Rallidis LS, Pitsavos C, Stefanadis C, Kremastinos D. Cigarette smoking and myocardial infarction in young men and women: a case-control study. Int J Cardiol. 2007;116(3):371-375.

11. Doll R, Peto R, Boreham J, Sutherland I. Mortality in relation to smoking: 50 years' observations on male British doctors. BMJ. 2004;328(7455):1519.

12. Teo KK, Ounpuu S, Hawken S, et al; for INTERHEART Study Investigators. Tobacco use and risk of myocardial infarction in 52 countries in the INTERHEART study: a case-control study. Lancet. 2006;368(8536):647-658.
13. Van Domburg RT, op Reimer WS, Hoeks SE, Kappetein AP, Bogers AJ. Three life-years gained from smoking cessation after coronary artery bypass surgery: a 30-year follow-up study. Am Heart J. 2008;156(3):473-476.

14. Sargent JD, Demidenko E, Malenka DJ, Li Z, Gohlke H, Hanewinkel R. Smoking restrictions and hospitalization for acute coronary events in Germany. Clin Res Cardiol. 2012;101(3):227-235.

15. Hata Y, Nakajima K. Life-style and serum lipids and lipoproteins. J Atheroscler Thromb. 2000;7(4):177-197.

16. Hurrell C, Wietlisbach V, Jotterand V, et al. High prevalence of major cardiovascular risk factors in first-degree relatives of individuals with familial premature coronary artery disease: the GENECARD project. Atherosclerosis. 2007;194(1):253-264.

17. Andresdottir MB, Sigurdsson G, Sigvaldason H, Gudnason V; for Reykjavik Cohort Study. Fifteen percent of myocardial infarctions and coronary revascularizations explained by family history unrelated to conventional risk factors: the Reykjavik Cohort Study. Eur Heart J. 2002;23(21):1655-1663.

18. Patel MJ, de Lemos JA, Philips B, et al. Implications of family history of myocardial infarction in young women. Am Heart J. 2007; 154(3):454-460.

19. Sesso HD, Lee IM, Gaziano JM, Rexrode KM, Glynn RJ, Buring JE. Maternal and paternal history of myocardial infarction and risk of cardiovascular disease in men and women. Circulation. 2001; 104(4): 393-398.

20. Philips B, de Lemos JA, Patel MJ, McGuire DK, Khera A. Relation of family history of myocardial infarction and the presence of coronary arterial calcium in various age and risk factor groups. Am J Cardiol. 2007;99(6):825-829.

21. Warren TY, Barry V, Hooker SP, Sui X, Church TS, Blair SN. Sedentary behaviors increase risk of cardiovascular disease mortality in men. Med Sci Sports Exerc. 2010;42(5):879-885.

22. Sofi F, Abbate R, Gensini GF, Casini A. Accruing evidence on benefits of adherence to the Mediterranean diet on health: an updated systematic review and meta-analysis. Am J Clin Nutr. 2010;92(5):1189-1196.

23. Bartnik M, Rydén L, Malmberg K, et al; for Euro Heart Survey Investigators. Oral glucose tolerance test is needed for appropriate classification of glucose regulation in patients with coronary artery disease: a report from the Euro Heart Survey on Diabetes and the Heart. Heart. 2007;93(1):72-77.

24. Völler H, Reibis R, Pittrow D, et al. Secondary prevention of diabetic patients with coronary artery disease in cardiac rehabilitation: risk factors, treatment and target level attainment. Curr Med Res Opin. 2009;25(4):879-890.

25. Gillies CL, Abrams KR, Lambert PC, et al. Pharmacological and lifestyle interventions to prevent or delay type 2 diabetes in people with impaired glucose tolerance: systematic review and meta-analysis. $B M J$. 2007;334(7588):299-302.

26. Drechsler K, Fikenzer S, Sechtem U, et al. The Euro Heart Survey Germany: diabetes mellitus remains unrecognized in patients with coronary artery disease. Clin Res Cardiol. 2008;97(6):364-370.

27. De la Hera JM, Delgado E, Hernández E, et al. Prevalence and outcome of newly detected diabetes in patients who undergo percutaneous coronary intervention. Eur Heart J. 2009;30(21):2614-2621.

28. Lankisch M, Füth R, Schotes D, et al. High prevalence of undiagnosed impaired glucose regulation and diabetes mellitus in patients scheduled for an elective coronary angiography. Clin Res Cardiol. 2006;95(2):80-87.

29. Knudsen EC, Seljeflot I, Abdelnoor M, et al. Abnormal glucose regulation in patients with acute ST-elevation myocardial infarction: a cohort study on 224 patients. Cardiovasc Diabetol. 2009;8:6-14.

30. Pineda J, Marín F, Marco P, et al. The prognostic value of biomarkers after a premature myocardial infarction. Int J Cardiol. 2010;143(3): 249-254.

31. Khot UN, Khot MB, Bajzer CT, et al. Prevalence of conventional risk factors in patients with coronary heart disease. JAMA. 2003;290(7): 898-904. 
32. Erqou S, Kaptoge S, Perry PL, et al; for Emerging Risk Factors Collaboration. Lipoprotein(a) concentration and the risk of coronary heart disease, stroke, and nonvascular mortality. JAMA. 2009;302(4): 412-423.

33. Clarke R, Peden JF, Hopewell JC, et al; for PROCARDIS Consortium. Genetic variants associated with $\mathrm{Lp}$ (a) lipoprotein level and coronary disease. N Engl J Med. 2009;361(26):2518-2528.

34. Pineda J, Marín F, Marco P, et al. Premature coronary artery disease in young (age $<45$ ) subjects: interactions of lipid profile, thrombophilic and haemostatic markers. Int J Cardiol. 2009;136(2):222-225.

35. Bassand JP, Hamm CW, Ardissino D, et al; for Task Force for Diagnosis and Treatment of Non-ST-Segment Elevation Acute Coronary Syndromes of European Society of Cardiology. Guidelines for the diagnosis and treatment of non-ST-segment elevation acute coronary syndromes. Eur Heart J. 2007;28(13):1598-1660.

36. Sarrafzadegan N, Rabiei K, Kabir A, et al. Changes in lipid profile of patients referred to a cardiac rehabilitation program. Eur J Cardiovasc Prev Rehabil. 2008;15(4):467-472.

37. Perk J, De Backer G, Gohlke H, et al; for Fifth Joint Task Force of the European Society of Cardiology and Other Societies on Cardiovascular Disease Prevention in Clinical Practice; European Association for Cardiovascular Prevention and Rehabilitation. European guidelines on cardiovascular disease prevention in clinical practice (version 2012). Eur Heart J. Epub May 3, 2012.

38. Grundy SM, Brewer HB Jr, Leeman JI, Smith SC Jr, Lenfant C; for American Heart Association; National Heart, Lung, and Blood Institute. Definition of metabolic syndrome: report of the National Heart, Lung, and Blood Institute/American Heart Association conference on scientific issues related to definition. Circulation. 2004;109(3):433-448.

39. Baigent C, Keech A, Kearney PM, et al; for Cholesterol Treatment Trialists' (CTT) Collaborators. Efficacy and safety of cholesterollowering treatment: prospective meta-analysis of data from 90,056 participants in 14 randomised trials of statins. Lancet. 2005;366(9493): 1267-1278.
40. Franklin K, Goldberg RJ, Spencer F, et al; for GRACE Investigators. Implications of diabetes in patients with acute coronary syndromes: the Global Registry of Acute Coronary Events. Arch Intern Med. 2004;164(13):1457-1463.

41. Rydén L, Standl E, Bartnik M, et al; for Task Force on Diabetes and Cardiovascular Diseases of the European Society of Cardiology (ESC); European Association for the Study of Diabetes (EASD). Guidelines on diabetes, pre-diabetes, and cardiovascular diseases: executive summary. Eur Heart J. 2007;28(1):88-136.

42. Kannel WB, Vasan RS. Triglycerides as vascular risk factors: new epidemiologic insights. Curr Opin Cardiol. 2009;24(4):345-350.

43. Lavie CJ, Milani RV. Cardiac rehabilitation and exercise training in secondary coronary heart disease prevention. Prog Cardiovasc Dis. 2011;53(6):397-403.

44. Vanhees L, Rauch B, Piepoli M, et al; for EACPR writing group. Importance of characteristics and modalities of physical activity and exercise in the management of cardiovascular health in individuals with cardiovascular disease (Part III). Eur J Prev Cardiol. Epub May 25, 2012.

45. Nocon M, Hiemann T, Müller-Riemenschneider F, Thalau F, Roll S, Willich SN. Association of physical activity with all-cause and cardiovascular mortality: a systematic review and meta-analysis. Eur J Cardiovasc Prev Rehabil. 2008;15(3):239-246.

46. Busse R. Disease management programs in Germany's statutory health insurance system. Health Aff (Millwood). 2004;23(3):56-67.

47. Cacoub PP, Zeymer U, Limbourg T, et al; for REACH Registry Investigators. Effects of adherence to guidelines for the control of major cardiovascular risk factors on outcomes in the REduction of Atherothrombosis for Continued Health (REACH) Registry Europe. Heart. 2011;97(8):660-667.

48. EUROASPIRE I and II Group; European Action on Secondary Prevention by Intervention to Reduce Events. Clinical reality of coronary prevention guidelines: a comparison of EUROASPIRE I and II in nine countries. Lancet. 2001;357(9261):995-1001.
Vascular Health and Risk Management

\section{Publish your work in this journal}

Vascular Health and Risk Management is an international, peerreviewed journal of therapeutics and risk management, focusing on concise rapid reporting of clinical studies on the processes involved in the maintenance of vascular health; the monitoring, prevention and treatment of vascular disease and its sequelae; and the involvement of

\section{Dovepress}

metabolic disorders, particularly diabetes. This journal is indexed on PubMed Central and MedLine. The manuscript management system is completely online and includes a very quick and fair peer-review system, which is all easy to use. Visit http://www.dovepress.com/ testimonials.php to read real quotes from published authors. 